\title{
Sustainable Value and Cleaner Production - research and application in 19 Portuguese SME
}

\author{
João Henriques, Justina Catarino*
}

LNEG, Estrada do Paço, Lisboa, Portugal

\section{A R T I C L E I N F O}

\section{Article history:}

Received 19 June 2013

Received in revised form

10 January 2014

Accepted 9 February 2014

Available online 12 March 2014

\section{Keywords:}

Sustainable Value

Cleaner Production

Eco-efficiency

Value analysis

SME

\begin{abstract}
A B S T R A C T
Eco-efficiency aims at improving the economic and ecological efficiency of companies, attaining a higher Value with fewer inputs, materials and energy, more outputs but fewer wastes. The result of implementing this strategy is the delivery of products and services that satisfy human needs, at lower costs while reducing the ecological impacts and resource intensity. This means a higher Value for companies, defined as the relationship between the satisfaction of needs and the resources used in achieving that satisfaction, as well as the increase of their competitiveness.

The purpose of this research was to develop the Sustainable Value concept using the synergies between tools from Value Management, Value Analysis and from Eco-efficiency, Cleaner Production. The result is an indicator that integrates the three aspects of Sustainability: economic, environment and social and enables the monitoring of the evolution of those aspects in a company.

The aim of this approach is to increase the Sustainable Value of the study subject, this being defined as the specific subject to which the methodology is applied, either a product or a process in a company. The satisfaction levels are evaluated considering environmental and social aspects. The resources used to attain that satisfaction of needs are also characterized in an explicit way in terms of environmental, social and economic aspects.

The proposed Sustainable Value methodology, with an eight phases working plan, developed by a team, was validated by undertaking three projects, involving 19 Small and Medium Enterprises where Sustainable Value concept was implemented. They represent a wide range of activity areas in different regions of the country, covering almost the whole Portuguese territory.

The application of the proposed methodology in the different companies shows the benefits concerning the inputs reduction (water, energy and materials) as well as emissions and waste reduction. The increase of the company's productivity and collaborators social welfare is also highlighted. Performance, costs and sustainable value variations are quantified.

A first important conclusion that can be taken from the reported experiences is that the use of Sustainable Value Methodology enables the diagnosis of the main problems related to processes and products and the quantification of the used resources, and takes into account the three aspects of Sustainability: economic, environmental and social.

Another conclusion is the applicability of the methodology to companies of different size and sectors. The same happens and is confirmed in existent literature about the subject with other approaches.

The improvement of Sustainable Value of the study subjects is reflected in the competitiveness of the companies.

Some suggestions about conditions that must be fulfilled for the success of the introduction and implementation of this approach in a company are also presented.
\end{abstract}

(c) 2014 Elsevier Ltd. All rights reserved.

\footnotetext{
* Corresponding author. Tel.: +351 210924600.

E-mail address: justina.catarino@lneg.pt (J. Catarino).
}

\section{Introduction}

In 1992 the World Business Council for Sustainable Development (WBCSD), stated that eco-efficiency is achieved by the delivery of competitively priced goods and services that satisfy human needs and bring quality of life, while progressively 